\title{
COMPOSITIONAL CHANGES OF MAJOR CHEMICAL COMPOUNDS IN GREEK CAROB PODS DURING DEVELOPMENT
}

\author{
A.S. Vekiari ${ }^{1 *}$, G. Ouzounidou ${ }^{1}$, G. Gork ${ }^{2}$, M. Ozturk ${ }^{3}$ and M. Asfi ${ }^{3}$ \\ ${ }^{1}$ National Agricultural Research Foundation, Institute of Technology of Agricultural Products, \\ Lykovrissi, Athens, Greece \\ ${ }^{2}$ Mugla University, Department of Biology, Mugla, Turkey \\ ${ }^{3}$ Ege University, Department of Botany, Bornova, Izmir, Turkey
}

(Received February 9, 2011; revised July 24, 2012)

\begin{abstract}
Because of the strong association with health benefits of some chemical compounds contained in carob fruit the composition of chemical substances of two common type carob pods (Ceratonia siliqua L.) and their changes during fruit developing in two periods of harvesting were reported. Samples were originated from a site near Rethymno, Crete Island, at an altitude of $100 \mathrm{~m}$ above the sea level. The moisture content determined through sample's drying in $70{ }^{\circ} \mathrm{C}$ under vacuum, sugars by HPLC (high pressure liquid chromatography), total polyphenols by ultraviolet/visible (UV/Vis) and fatty acids by gas chromatography (GC) in the fleshy and wild types were determined at three stages of development. Principal sugars found were glucose, fructose and sucrose. The predominant fatty acid was linoleic acid (n-6) followed by oleic, palmitic and then linolenic (n-3) fatty acids. The total unsaturated fatty acids content was two times higher than the content of total saturated fatty acids in fully-developed carob pod. The ratio n-6/n-3 was under 5 , showing a good equilibrium between the two essential fatty acids. The fully developed fruits of both varieties revealed lower contents of polyphenols, proteins and sugars compared with their previous growth stages. The fleshy carob pods exceed the wild variety in concentration of proteins, sugars and fatty acids, while the wild variety exceeds the fleshy in polyphenols concentration.
\end{abstract}

KEY WORDS: Carob pods, Ceratonia siliqua L., Fatty acids, Polyphenols, Sugars

\section{INTRODUCTION}

The carob tree (Ceratonia siliqua L.) has been grown since antiquity in most countries of the Mediterranean basin, usually in mild and dry places with poor soils $[1,2]$. It is a native tree of the Mediterranean and Middle East, and it was first introduced in the Southwest in 1856 by Spanish missionaries. The genus name Ceratonia comes from the uniform seeds, which were once used as a standard measure of weight or carat. The world production of carob pods is estimated to be around the 32000 tons/year, the leading producer being Spain followed by Italy, Portugal, Morocco, Greece, Cyprus, Turkey, Algeria [3, 4].

Carob pods are not only edible, but also rich in sucrose and protein while they are poor in fat. They contain vitamins A and B and several minerals $[3,5]$. The most valuable protein is that received from seed germ [6], which is used as alternative protein source for the industry. The kind of polyphenols contained in carobs are especially highly condensed tannins. Marakis et al. [7] have studied tannins of eight carob Greek varieties, while other researchers have studied the effect of condensed tannins in carob pods on feed intake [8]. The main use of economical importance of carob is as a cocoa substitute [2] that has slightly different taste than chocolate, it is fat-free, rich in pectin, is non-allergic and has only one third the calories of that of chocolate. The bean pulp is also mixed with other feed to obtain a high quality, nutritious, and superb tasting fodder for horses, cattle, and goats. Therefore, the most important use of the pods lies in the production of gum, taken from the seeds after shuttering and separation and used in many commercial food products as a thickening agent as well as textile industry [9].

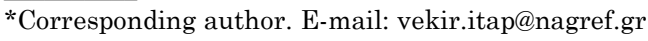


Due to their chemical composition, the carobs are used in food and in medicine. In terms of their medicinal uses carob pods have demonstrated interesting anti-cardiovascular and antioxidant properties, apparently related to phenolic compounds that they contain. Research indicates that polyphenols, because of their strong antioxidant activity, play protective role against oxidative stress thus, they have potential health benefits $[5,10,11]$. In addition, as carobs are rich in insoluble fibres they might improve cholesterol profile like other sources of fibres [12, 13]. Generally, according to Myers et al. [14], Pineda et al. [15] and Ozturk et al. [16], the Mediterranean basin is a conservation sanctuary, a historical refuge and a baseline for life, representing a rich heritage both for the exploration of new resources (food, medicines, energy, etc.), as well as the traditional culture of the inhabitants in the basin. Crete Island flora is very diverse due to its geography and its geomorphology and for this reason is very much worth investigating. In the present study, chemical analysis was carried out on carob fruits collected from Crete Island (South Greece) and at a height of $\sim 100 \mathrm{~m}$ from the sea level, where the plant is cultivated, in order to obtain information on the chemical characteristics of main carob cultivars in the above areas.

Considering the biological importance of some chemical compounds, their strong association with health benefits and also the absence of relative information on Greek carobs, an effort has been made to compare the chemical composition of the most common carob varieties in Greece. Changes on the composition of proteins, phenols, fatty acids (including n-6 and n-3) and sugars of carob pods during fruit development were studied as well.

\section{EXPERIMENTAL}

\section{Site description}

The carob tree (Ceratonia siliqua L.) typically blooms from September to November and 11 months pass from flowering to fruit ripening. The bean is green at the start and turns dark brown when ripe, when it becomes quite large, ranging from 8 to $25 \mathrm{~cm}$, and holds 5 to 15 seeds. The studied area was cited at an altitude of $100 \mathrm{~m}$ above the sea level, near Rethymno city in Crete Island, South Greece. Its climatic parameters (photosynthetic active radiation and air temperature) were measured using a LI-6400 analyzer (open system) connected to a 6400-40 leaf chamber (LI-COR Inc., Lincoln, NE, USA) during 2007 and 2008 in three dates that cover the period of spring, (the beginning of May), of summer (the end of June) and of autumn (the end of October).

\section{Sampling}

Samples of 20 pods were randomly harvested in the morning, from 10 adult trees $2.0-2.5 \mathrm{~m}$ tall, healthy and with no infection, of fleshy and wild variety, from similar positions and orientations in the canopy facing southwards on the trees. Three growth stages of carob pods were selected, when immature (green colored in May), mature (light brown colored in July) and fully mature (dark brown colored in September). The fruits in fleshy variety were thick, long and flat with a dark brown colour, while in wild variety they were thin, long and flat, sometimes curled with a light brown colour [17].

\section{Laboratory methods}

The collected fruits were brought to the laboratory in polyethylene bags, seeds were removed and shelled pods were cut in big pieces. The pod pieces were blended and a part used for the moisture content determination was dried in $70{ }^{\circ} \mathrm{C}$ under vacuum [18], the rest was lyophillized. 
The analyses were carried out on the dry pulp homogenized and ground in electric mills to particles.

\section{Polyphenol and protein determination}

The total polyphenols were extracted according to the method described by Ayaz et al. [4] and determined by the Folin-Ciocalteu method with calibration curves for gallic acid. A spectrophotometer UV/Vis was used at a wavelength of $725 \mathrm{~nm}$. Data were expressed as $\mathrm{mg}$ gallic acid equivalents. Protein concentration (expressed \%) was determined by the method of Kjeldahl [19].

\section{Analysis of fatty acids}

The fats were esterified by direct methylization in capsules and subjected to extraction. Fatty acid composition of the oils was determined by gas chromatography (GC) as fatty acid methyl esters (FAME). FAME was prepared by saponification /methylation with sodium methylate according to the European Union Commission modified Regulation EEC 2568 method [20]. Samples were analysed using a Varian CP-3800 gas chromatography equipped with a FID (flame ionization detector) detector (Varian, Middelburg, The Netherlands) and a Stabilwaxtype analytical column, (30 m x $0.32 \mathrm{~mm}$ i.d. x $0.25 \mu \mathrm{m})$ (J\&W Scientific Inc. Rancho Cordova, CA, USA). Helium was used as the carrier gas.

\section{Sugar analysis}

The sugar content was determined by the method described by Perez et al. [21]. Sucrose, fructose and glucose were determined as described by Folkes and Grane [22]. The samples were analyzed with a Hewlet Packard, Agilent series 1100 HPLC (high pressure liquid chromatography) equipped with a G1362A Refractive Index and a G1311A QuatPump. An MZ - LiChrosphere-NH2/5 $\mu \mathrm{m}$ - analytical column $(250 \mathrm{x} 4 \mathrm{~mm})$ and a $20 \mu \mathrm{L}$ loop injector were used. The mobile phase was a mixture of HPLC grade water/acetonitrile (75:25) at a flow rate of $1.3 \mathrm{~mL} / \mathrm{min}$.

\section{Statistical analysis}

In all cases the assays were carried out during 2007 and 2008 on three growth stages per year, in triplicate. The statistical analysis was performed using the SPSS 10.0 software (SPSS Inc, Chicago, IL, USA). The results were subjected to a one-way ANOVA, using the Tukey test to check significant differences between means $(\mathrm{p}<0.05)$.

\section{RESULTS AND DISCUSSION}

The carob pod development follows a sigmoid growing curve like many other fruits and could be divided into three stages. In the first stage, after fertilization in October, during autumn and winter, the beans show hardly any increase in the weight (fresh and dry), which is due to slow growth. The second stage starts at the beginning of spring when the pod enters an active and fast growth period (April to June). In third stage, the fruit grows slowly, ripens and starts becoming dry after June and changes colour from green to brown [3]. This reflects the importance of investigating the differences in the quality characteristics of pods during the growth period. In view of this, the moisture, total polyphenols, proteins, sugars, and fatty acids variation were studied in two different varieties of carobs during development and the results are presented in Tables 1-3. 
Climatic parameters

Environmental factors can affect fruit growth and nutritional attributes. We emphasized at the two major factors, light and temperature, which have direct effects on chemical compounds biosynthesis. Mean values $( \pm \mathrm{SD})$ of photosynthetically active radiation $(\mathrm{PAR})$ and day air temperature $\left(\mathrm{T}_{\text {air }}\right)$ during sampling months in Rethymnon area of Crete in 2007 and 2008 were measured. PAR $\left(\mu \mathrm{mol} \mathrm{m} \mathrm{m}^{-2} \mathrm{~s}^{-1}\right)$ and $\mathrm{T}_{\text {air }}\left({ }^{\circ} \mathrm{C}\right)$ max values were recorded at 14:00 p.m., while the min values at 7:00 am. The values of PAR varied from 350 to $1320 \mu \mathrm{mol} \mathrm{m}^{-2} \mathrm{~s}^{-1}$ for green carobs, from 740-1920 for mature carobs and from $250-1100 \mu \mathrm{mol} \mathrm{m} \mathrm{m}^{-2} \mathrm{~s}^{-1}$ for fully mature carobs. Concerning the temperature, it varied from $18-28{ }^{\circ} \mathrm{C}$ for the first growth stage, from $22-$ 36 in the second and from $15-25^{\circ} \mathrm{C}$ in the third growth stage.

\section{Moisture and protein content}

Both varieties possessed moisture content much higher than $50 \%$ in the first stage, which diminished sharply from the first stage to the second (by more than 85 and $89 \%$ in wild and fleshy type, respectively) and more wildly in the next samplings (Table 2). More specifically, moisture content ranged from 78.4 to $9.4 \%$ in wild and from 75.4 to $9.1 \%$ in fleshy variety.

In addition, protein content followed a similar pattern showing a significant drop during development. Their concentration varied from 8.3 to $4.1 \%$ and from 10.4 to $5.1 \%$ in wild and fleshy carobs, respectively. Similar results have been found by Battle and Tous [3]. In the $3^{\text {rd }}$ stage the protein content of carobs decreased by 50 and $40 \%$ in wild and fleshy variety respectively, as compared with the $1^{\text {st }}$ stage (Table 2 ). At any stage, fleshy pods contained higher protein concentrations than the wild. It is well known that both moisture and protein content decreased during ripening due to the higher respiration rates as well as to the large rise in protease activity associated with a depletion of reserves [23-25].

Table 1. Moisture, total polyphenols and protein content (\% on the basis of dry matter) of two varieties of Greek carob pods at the three growth stages.

\begin{tabular}{|c|c|c|c|c|}
\hline Moisture & \multicolumn{2}{|c|}{ Wild } & Mean & SD \\
\hline Samplings & Mean & SD & 75.4 & 0.35 \\
\hline $1^{\text {st }}$ & 78.4 & 0.85 & 8.5 & 1.48 \\
\hline $2^{\text {nd }}$ & 11.4 & 0.42 & 9.1 & 0.99 \\
\hline $3^{\text {rd }}$ & 9.4 & 0.85 & Mean & SD \\
\hline Total polyphenols & Mean & SD & 21.5 & 0.48 \\
\hline $1^{\text {st }}$ & 22.5 & 0.56 & $2.5^{*}$ & 0.63 \\
\hline $2^{\text {nd }}$ & 4.3 & 0.68 & $1.8^{*}$ & 0.84 \\
\hline $3^{\text {rd }}$ & 3.8 & 0.47 & Mean & SD \\
\hline Protein & Mean & SD & $10.4^{*}$ & 0.11 \\
\hline $1^{\text {st }}$ & 8.3 & 0.32 & $5.1^{*}$ & 0.32 \\
\hline $2^{\text {nd }}$ & 4.0 & 0.26 & $6.4^{*}$ & 0.18 \\
\hline $3^{\text {rd }}$ & 4.1 & 0.15 & & \\
\hline
\end{tabular}

The values represent the means of triplicate analyses \pm SD. *Mean values in the same row differ significantly at $p$ $\leq 0.05$.

\section{Polyphenol content}

Phenolic compounds, non-nutrient but biologically active secondary plant metabolites which can act as antioxidants, are widely distributed in the plant kingdom and are present in many foods and beverages of plant origin. The acceptability of fruit and vegetables for human consumption may be affected by their content of phenolics [4]. In the present study, their 
concentration ranged from 22.5 to $3.8 \%$ in the wild and from 21.5 to $1.8 \%$ in the fleshy variety (on dry weight basis) expressed in gallic acid. Fleshy pods contained significantly lower polyphenol concentration (by 52\%) in the last growth stage compared to the wild pods. Other studies have reported that carob pods contain $6.1 \%$ of total polyphenols [7]. Significant reductions of the total phenolic compounds, which are of exceptionally high biological activity and astringency and an important index of fruit quality [26] were recorded during the ripening period. According to Silanikove et al. [8] this is due to the substantial polymerization and condensation of carob tannins resulting in loss of astringency in the ripe fruit. The highest loss was observed at the $3^{\text {rd }}$ stage of growth by 83 and $92 \%$ in wild and fleshy variety, respectively, compared to the $1^{\text {st }}$ stage (Table 1 ).

Makris and Kefalas [26] indicated that efficient polyphenol extraction from carob pods with appreciable antioxidant capacity is an evidence for the high potential of carobs, a cost effective source of value-added polyphenolic phytochemicals might be achieved employing aqueous acetone. The main constituents of carob polyphenols were found to be condensed tannins [7]. The variation in polyphenols within and among carob pods is attributed to the geographical origin, variety, conditions of cultivation and degree of maturation $[4,27]$, as it was shown by our results.

Table 2. Fatty acid composition (\% on the basis of dry matter) of two varieties of Greek carob pods at the three growth stages.

\begin{tabular}{|l|l|l|l|l|l|l|}
\hline Fatty acids & Fleshy 1st & Fleshy 2nd & Fleshy 3rd & Wild 1st & Wild 2nd & Wild 3rd \\
\hline Caproic acid (C6:0) & $0.11 \pm 0.04$ & $3.81 \pm 0.13$ & $0.55 \pm 0.07$ & $0.10 \pm 0.71$ & $0.40 \pm 0.07$ & $0.19 \pm 0.06$ \\
\hline Caprylic acid (C8:0) & $0.035 \pm 0.01$ & $0.86 \pm 0.06$ & $0.24 \pm 0.06$ & $0.04 \pm 0.03$ & $0.32 \pm 0.04$ & $0.18 \pm 0.03$ \\
\hline Capric acid (C10:0) & $0.65 \pm 0.21$ & $4.69 \pm 0.16$ & $0.34 \pm 0.03$ & $0.62 \pm 0.17$ & $0.80 \pm 0.06$ & $0.28 \pm 0.10$ \\
\hline Lauric acid (C12:0) & $0.055 \pm 0.03$ & $0.14 \pm 0.06$ & $0.06 \pm 0.03$ & $0.09 \pm 0.03$ & $0.10 \pm 0.04$ & $0.08 \pm 0.01$ \\
\hline Tridecanoic acid (C13:0) & $0.09 \pm 0.01$ & $0,18 \pm 0.03$ & $0.08 \pm 0.04$ & $0.15 \pm 0.06$ & $0.23 \pm 0.03$ & $0.09 \pm 0.01$ \\
\hline Myristic acid (C14:0) & $0.21 \pm 0.10$ & $0.16 \pm 0.06$ & $0.82 \pm 0.44$ & $0.27 \pm 0.04$ & $1.09 \pm 0.2$ & $0.68 \pm 0.07$ \\
\hline Pentadecanoic acid (C15:0) & $0.11 \pm 0.06$ & $0.07 \pm 0.03$ & $0.16 \pm 0.04$ & $0.15 \pm 0.06$ & $0.23 \pm 0.07$ & $0.18 \pm 0.03$ \\
\hline Pentadecenoic acid (C15:1) & $0.14 \pm 0.06$ & $0.69 \pm 0.16$ & $0.41 \pm 0.27$ & $0.13 \pm 0.04$ & $0.51 \pm 0.06$ & $0.29 \pm 0.07$ \\
\hline Palmitic acid (C16:0) & $17.85 \pm 0.49$ & $18.62 \pm 0.54$ & $20.78 \pm 0.25$ & $20.03 \pm 0.33$ & $22.05 \pm 0.21$ & $20.73 \pm 0.18$ \\
\hline Palmitoleic acid (C16:1) & $0.34 \pm 0.08$ & $0.46 \pm 0.06$ & $0.51 \pm 0.09$ & $0.26 \pm 0.07$ & $0.68 \pm 0.03$ & $0.57 \pm 0.08$ \\
\hline Margaric acid (C17:0) & $0.55 \pm 0.07$ & $0.41 \pm 0.06$ & $0.48 \pm 0.11$ & $0.69 \pm 0.10$ & $0.83 \pm 0.06$ & $0.75 \pm 0.16$ \\
\hline Stearic acid (C18:0) & $2.54 \pm 0.08$ & $2.83 \pm 0.24$ & $3.49 \pm 0.27$ & $3.02 \pm 0.17$ & $3.39 \pm 0.18$ & $3.61 \pm 0.10$ \\
\hline Oleic acid (C18:1) & $21.59 \pm 0.16$ & $38.05 \pm 0.64$ & $40.48 \pm 0.54$ & $13.63 \pm 0.61$ & $34.73 \pm 0.25$ & $38.45 \pm 0.40$ \\
\hline Linoleic acid (C18:2 n6) & $33.22 \pm 0.11$ & $9.42 \pm 0.68$ & $16.14 \pm 0.34$ & $42.23 \pm 0.47$ & $11.56 \pm 0.18$ & $11.65 \pm 0.49$ \\
\hline$\alpha$-Linolenic acid (C18:3 n3) & $9.96 \pm 0.06$ & $2.15 \pm 0.21$ & $2.00 \pm 0.28$ & $11.79 \pm 0.27$ & $2.58 \pm 0.25$ & $2.50 \pm 0.57$ \\
\hline Arachidic acid (C20:0) & $0.84 \pm 0.08$ & $1.28 \pm 0.31$ & $1.40 \pm 0.42$ & $0.79 \pm 0.20$ & $1.71 \pm 016$ & $1.62 \pm 0.24$ \\
\hline $\mathrm{n}$ - 6/n - 3 & 3.33 & 4.38 & 8.07 & 3.58 & 4.48 & 4.66 \\
\hline Unsaturated/Saturated & 2.52 & 1.47 & 1.9 & 2.62 & 1.6 & 1.88 \\
\hline MCSFAs & 0.85 & 9.5 & 1.19 & 0.85 & 1.62 & 0.73 \\
\hline LCSFAs & 22.1 & 23.37 & 27.13 & 24.95 & 29.3 & 27.57 \\
\hline LCUFAs & 65.25 & 50.77 & 59.54 & 68.01 & 50.06 & 53.46 \\
\hline
\end{tabular}

The values represent the means of triplicate analyses \pm SD. MCSFAs: medium chain saturated fatty acids (C6-

C12). LCSFAs: Long chain saturated fatty acids (over C14). LCUFAs: Long chain unsaturated fatty acids.

\section{Fatty acids profile}

The typical gas chromatograph of fatty acids in the studied carobs is depicted in Figure 1, while their concentrations in the pods, expressed as percentage of the total fatty acids, are given in Table 2. Our data constitute the first report on quantification of fatty acids in developing Greek carob pods and they show that there is significant variation in the percentage of fatty acids during pod development. The pod was rich in linoleic and $\alpha$-linolenic acids in the first stage, 
which then transfer into oleic acid followed by the saturated palmitic fatty acid. These findings coincide with the findings of other researchers [28]. The level of oleic acid content increased during the ripening phase (Table 3 ), while the linoleic and $\alpha$-linolenic acids decreased. The oleic acid content varied from 21.59 to $40.48 \%$ in fleshy and from 13.63 to $38.45 \%$ in wild variety, while the linoleic varied from 33.22 to $16.14 \%$ in fleshy and from 42.23 to $11.65 \%$ in wild variety, respectively. The concentration of linoleic acid decreased with progressive pod maturity, indicating the less or no conversion to fatty acids during chain elongation [29]. The majority of saturated and mono- unsaturated fatty acids increased gradually, while the polyunsaturated fatty acids sharply decreased.

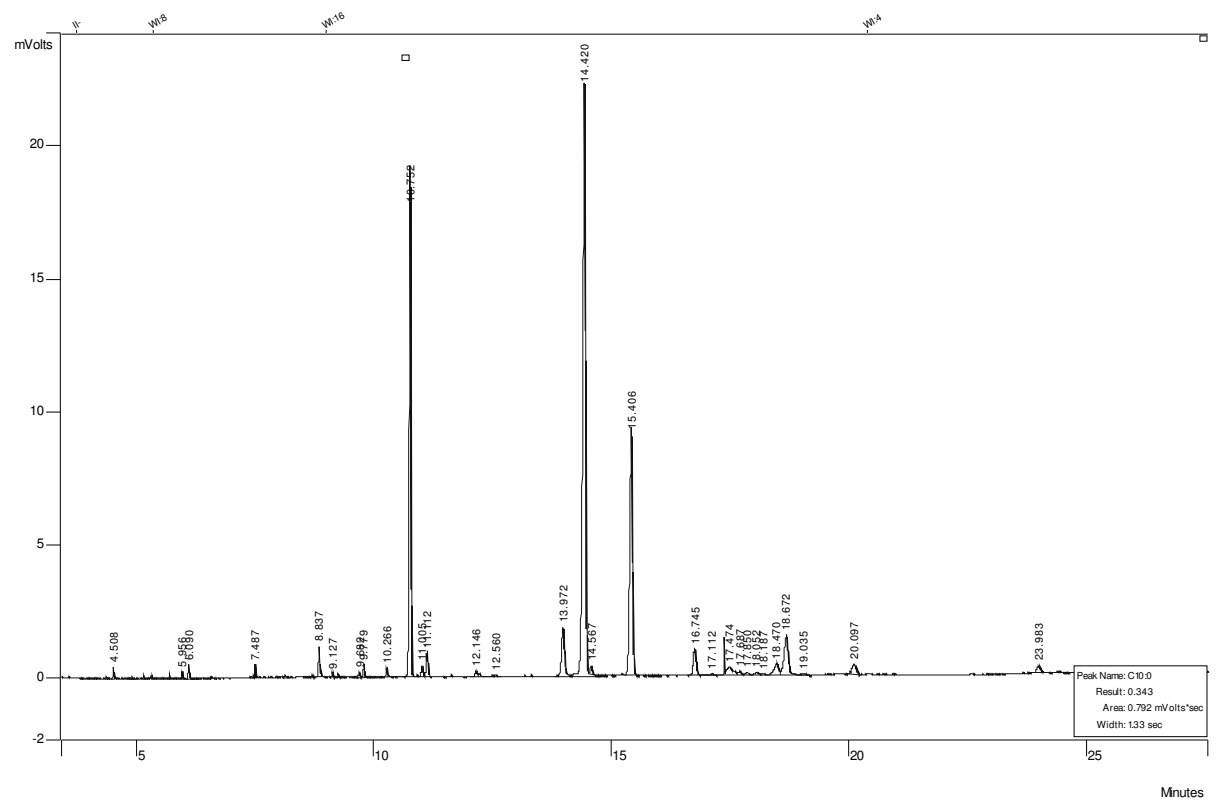

Figure 1. A typical gas chromatogram of fatty acids of fleshy carob pods at the third growth stage (full development). 10.752: palmitic acid, 13.97: stearic acid, 14.42: oleic acid, 15.406: linoleic acid, 16.745: $\alpha$-linolenic acid.

The ratio of unsaturated to saturated fatty acids varied from 2.52 to 1.9 in fleshy and from 2.62 to 1.88 in wild carobs, respectively. This ratio presented the lowest value in samples harvested early in spring, indicating that the environmental conditions during this period can help in chain elongations and desaturation of fatty acids. The availability of abundant moisture may be one of the reasons. Moisture may be ensuring enough oxygen supply for the desaturation to carry out the unsaturation of long chain fatty acids. Since the pod development during next months coincided with the non-rainy season, the trends to be coinciding with the degree of stress that the carob faces [29]. In mature carob pods the content of total unsaturated fatty acids was two times higher than the content of total saturated fatty acids. This is in contrast with other studies, that they found equal amount of saturated and unsaturated acids in the carob fat $[5,28$, 30]. According to Dubois et al. [31] the ratio n-6/n-3 should be 5 or less, in order this ratio to be used as an index of good equilibrium between the two essential fatty acids. In our study, in most cases, this ratio was lower than 5. Despite the interest in ALA ( $\alpha$-linolenic acid), and the awareness of scientists and nutritionists regarding essential fatty acid intake, food product manufacturers tend to increase ALA in their goods to improve the shelf life of the products.

Bull. Chem. Soc. Ethiop. 2012, 26(3) 
Generally, they face a dilemma because, from the nutrition point of view, food products should contain more ALA, while the shelf life needs to be shortened.

Table 3. Sugar content ( $\%$ on the basis of dry matter) of two varieties of Greek carob pods at the three growth stages.

\begin{tabular}{|c|c|c|c|}
\hline Sugars & Growth stage & Wild & Fleshy \\
\hline \multirow{4}{*}{ Glucose } & $1^{\text {st }}$ & $13.6 \pm 0.71$ & $12.3 \pm 0.42$ \\
\cline { 2 - 4 } & $2^{\text {nd }}$ & $10.3 \pm 0.42$ & $9.7 \pm 0.71$ \\
\cline { 2 - 4 } Fructose & $3^{\text {rd }}$ & $8.5 \pm 0.71$ & $10.8 \pm 0.69^{*}$ \\
\cline { 2 - 4 } & $1^{\text {st }}$ & $3.3 \pm 0.28$ & $2.8 \pm 0.42$ \\
\cline { 2 - 4 } & $2^{\text {nd }}$ & $10.3 \pm 0.57$ & $5.1 \pm 0.96^{*}$ \\
\hline \multirow{3}{*}{ Sucrose } & $3^{\text {rd }}$ & $5.8 \pm 0.42$ & $6.3 \pm 0.42^{*}$ \\
\cline { 2 - 4 } & $1^{\text {st }}$ & $2.0 \pm 0.29$ & $5.1 \pm 0.28^{*}$ \\
\cline { 2 - 4 } & $2^{\text {nd }}$ & $16.0 \pm 0.42$ & $33.3 \pm 0.71^{*}$ \\
\hline & $3^{\text {rd }}$ & $21.4 \pm 0.70$ & $26.2 \pm 0.65^{*}$ \\
\hline /G+F & $1^{\text {st }}$ & 0.12 & $0.34^{*}$ \\
\hline & $2^{\text {nd }}$ & 0.19 & $1.57^{*}$ \\
\hline
\end{tabular}

The values represent the means of triplicate analyses \pm SD. *Mean values in the same row differ significantly at $\mathrm{p}$ $\leq 0.05 . \mathrm{S} / \mathrm{G}+\mathrm{F}$ ( sucrose/glucose+fructose).

Sugars

Sugar content of pods varies considerably according to the species, variety, physiological maturity, harvest season, climate and storage conditions. The ethanolic extracts of carob pod sampled in Greece showed that they contain mainly three types of sugars namely: sucrose, fructose and glucose, in general of non-reducing type, with sucrose as the principal constituent (Table 3). This is in accordance with the findings of Vardar et al. [32], Avallone et al. [27] and Ayaz et al. [4]; however lower quantities were found in comparison with their results. The three sugars together accounted for 33 and $43.3 \%$ at the maturity stage on the basis of total dry weight of the extracts, with sucrose predominating correspondingly for each location. Sucrose, one of the most important parameters for the assessment of the commercial quality of these fruits [27, 32 ] and the main transporter of fixed carbon and energy in plants [33] varied from 2.0 to $21.4 \%$ in the wild carobs and from 5.1 to $26.2 \%$ in fleshy type (Table 3 ) following by glucose and fructose. Our results agree with the findings of Ayaz et al. [4]. During the maturation period the fructose and sucrose contents increased, while glucose decreased.

Genetic and environmental factors may affect the qualitative and quantitative composition of the sugar fraction by altering the activity of the enzymes involved in synthesis and breakdown processes [34]. In the early growth stages, glucose content of carob fruits was high, but as ripening progressed the pattern of sucrose accumulation in the fruit showed at the beginning a sharp rise and a less marked increase thereafter, while the concentration of glucose decreased (Table 3) and this is in agreement with Davies [35]. Sucrose may be formed by glucose and fructose, as well as by the breakdown of the different carbohydrates present in other organs of the tree. The sucrose to reducing sugars ratio $(\mathrm{S} / \mathrm{G}+\mathrm{F})$ during the early stage of fruit growth remained very low; while that ratio sharply increased by $8-10$ times at wild and by 4.5 times at fleshy variety of carobs during the ripening period (Table 3 ). This rapid increase was related to the leveling off of weight and the accumulation of sucrose. Our results are similar with those of Villanueva et al. [34] and Ouzounidou et al. [36]. 


\section{CONCLUSIONS}

Carob fruit could be a significant cheap source of sugars and natural phenolics, for food industry, the importance of which is poorly investigated and evaluated. A progressive reduction of proteins, sugars, polyphenols and fatty acids content in carob fruit during development has been observed for both carob varieties, which can be attributed to different abilities of the plants to accumulate, synthesize or degrade these compounds during fruit growth and development. The fleshy carob pods revealed higher concentrations of proteins and sugars compared to the wild type. The chemical differentiation between the fleshy and the wild pod could be of genetic

origin and not of environmental differences, since the trees cultivated at the same climate conditions.

\section{ACKNOWLEDGEMENTS}

The present study was founded by GSRT and TUBITAK in the frame of Bilateral S\&T Cooperation between Greece and Turkey.

\section{REFERENCES}

1. Nunes, M.A.J.; Ramalho, D.C. Physiol. Plant 1992, 86, 381.

2. Ozturk, M.; Secmen, O.; Guvensen, A. For. Eng. J. 1995, 32, 5.

3. Batlle, I.; Tous, J. Carob Tree: Ceratonia siliqua L. IPGRI: Rome; 1997; pp 43-50.

4. Ayaz, F.A.; Torun, H.; Ayaz, S.; Correia, P.J.; Alaiz, M.; Sanz, C.; Gruz, J.; Strnad, M. J. Food Qual. 2007, 30, 1040.

5. Calixto, F.S.; Canellas, J. J. Sci. Food Agric. 1982, 33, 1319.

6. Maza, M.P.; Zamora, R.; Alaiz, M.; Hidalgo, F.J.; Millan, F.; Vioque, E. J. Sci. Food Agric. 1989, 46, 495.

7. Marakis, S.; Marakis, G.; Lambraki, M. Chim. Chron., N. Series 1997, $26,57$.

8. Silanikove, N.; Landau, S.; Kababya, D.; Bruckental, I.; Nitsan, Z. Livest. Sci. 2006, 99, 29.

9. Ahmed, M.; Vardar, Y. Phyton. 1975, 33, 63.

10. Arts, I.C.; Hollman, P.C. Am. J. Clin. Nutr. 2005, 81, 317S.

11. Kumazawa, S.; Taniguchi, M.; Suzuki, Y.; Shimura, M.; Kwon, M.-S.; Nakayama, T. J. Agric. Food Chem. 2002, 50, 373.

12. Evans, A.J.; Hood, R.L.; Oakenful, D.G.; Sidhu, G.S. Brit. J. Nutr. 1992, 68, 217.

13. Perez-Olleros, L.; Garcia-Cuevas, M.; Ruiz-Rosso, B.; Requejo, A. J. Sci. Food Agric. 1999, 79, 173.

14. Myers, N.; Mittermeier, R.A.; Mittermeier, C.G.da Fonseca, G.A.B.; Kent, J. Nature 2000, 403, 853.

15. Pineda, F.D.; De Miguel, J.M.; Casado, A.; Montalvo, J. La Diversidad Biologica de Espana, Vol. 15, Prentice Hall: Madrid; 2002; pp 75-77.

16. Ozturk, M.; Gucel, S.; Sacckali, S.; Gork, C.; Yarci, C.; Gork, G. Natural Environment and Culture in the Mediterranean Region, Efe, R.; Cravins, G.; Ozturk, M.; Atalay, I. (Eds.), Cambridge Scholars Press: UK; 2008.

17. Vardar, Y.; Secmen, O.; Ozturk, M. Separata de Portugaliae Acta Biologica, Lisboa. Serie A, (Port. Acta Biol.) 1980, 16, 75.

18. AOAC Official Methods of Analysis, J. AOAC Int., 15th ed., AOAC: Washington DC; 1990.

19. AOAC Official Methods of Analysis, J. AOAC Int., 14th ed., AOAC: Washington DC; 1984; p 346.

20. The Commission of the European Communities, Regulation No 2568/91, Offic. J. Europ. Commun. 1991, No L248. 
21. Perez, A.G.; Rios, J.J.; Sanz, C.; Oleas, J.M. J. Agric. Food Chem. 1997, 45, 3545.

22. Folkes, D.J.; Crane, L. HPLC in Food Analysis, Macrae, R. (Ed.), Academic Press: London; 1988; pp 71-72.

23. Burton, K.S. J. Hortic. Sci. 1988, 63, 103.

24. Vekiari, S.A.; Philippoussis, A.; Vitiniotis, S.; Diamantopoulou, P. Acta Hortic. Ishs. 2002, 579, 107.

25. Vekiari, S.A.; Papadopoulou, P.; Krystallis, A. J. Sci. Food Agric. 2004, 84, 485.

26. Makris, D.P.; Kefalas, P. Food Technol. Biotechnol. 2004, 42, 105.

27. Avallone, R.; Plessi, M.; Baraldi, M.; Monzani, A. J. Food Comp. Anal. 1997, 10, 166.

28. Rendina, N.; Lucisano, A.; Valletrisco, M. Nuova Chim. 1969, 45, 92.

29. Naresh Kumar, S.N.; Balakrishna, A. J. Food Qual. 2009, 32, 158.

30. Morton, J.F. Carob in Fruits of Warm Climates, Dowling, C.F. (Ed.), Morton: Miami, FL; 1987; pp 35-37.

31. Dubois, V.; Breton, S.; Linder, M.; Fanni, J.; Parmentier, M. Eur. J. Lipid Sci. Technol. 2007, 109, 710.

32. Vardar, Y.; Secmen, O.; Ahmed, M. Qual. Pl. Mater. Veget. 1972, 21, 367.

33. Vekiari, S.A.; Panagou, E.; Mallidis, C. J. Hort. Sci. Biotechnol. 2007, 82, 967.

34. Vilanueva, M.I.; Tenorio, M.D.; Esteban, M.A.; Mendoza, M.C. Food Chem. 2004, 87, 179.

35. Davies, W.N.L. J. Sci. Food Agric. 1971, 22, 83.

36. Ouzounidou, G.; Asfi, M.; Moustakas, M. VI International ISHS Symposium on Mineral Nutrition of Fruit Crops, Faro, Portugal; 2008; pp 84-87. 